\title{
Harlequin İktiyozisli Yenidoğanın Konfor Kuramına Göre Hemşirelik Bakımı: Olgu Sunumu
}

\section{Nursing Care According to the Comfort Theory of the Newborn with Harlequin Ichthyosis: Case Report}

\author{
${ }^{1}$ Cansu ARIKAN, ${ }^{2}$ Dilek MENEKȘE, ${ }^{2}$ Nursan ÇINAR \\ ${ }^{1}$ Sakarya Üniversitesi, Sağlık Bilimleri Enstitüsü, Hemşirelik Anabilim Dalı Yükseklisans Öğrencisi, Türkiye \\ ${ }^{2}$ Sakarya Üniversitesi, Sağlık Bilimleri Fakültesi, Çocuk Sağlığı ve Hastalıkları Hemşireliği Anabilim Dalı, Türkiye
}

Cansu Arkkan: https://orcid.org/0000-0001-5366-794X

Dilek Menekşe: https://orcid.org/0000-0003-0176-8778

Nursan Çınar: https://orcid.org/0000-0003-3151-9975

\begin{abstract}
ÖZ
Tüm konjenital iktiyozların en şiddetli olanı Harlequin iktiyoz, nadir görülen bir genetik cilt hastalığıdır. Yenidoğan derisi, çatlayan ve ayrılan kalın deri plakalarıyla kaplıdır. Harlequin iktiyozlu yenidoğanlar hipotermi/ hipertermi, dehidratasyon, solunum sıkıntıs1, hipoventilasyon, yetersiz beslenme, hipernatremi, nöbet ve cilt enfeksiyonu açısından yüksek risk altındadırlar. Yaşamsal açıdan ve prognozun seyri açısından hastaların tedavi ve özellikle hemşirelik bakımı çok önemlidir. Konfor kuramı temel insan gereksinimlerini karşılayamayan bireylerin holistik bir bakış açısıyla ferahlama, rahatlama, sorunların üstesinden gelme bileşenleriyle karşılanmasını sağlamaktadır. $\mathrm{Bu}$ olguda Harlequin iktiyoz tanısı alan yenidoğanın hemşirelik bakımı Konfor kuramı çerçevesinde gerçekleştirilmiştir.
\end{abstract}

Anahtar Kelimeler: Harlequin iktiyozis, hemşirelik, hemşirelik bakımı, konfor kuramı, yenidoğan

\section{ABSTRACT}

Harlequin ichthyosis, the most severe of all congenital ichthyosis, is a rare genetic skin disease. The newborn skin is covered with plates of thick skin that crack and split apart. Newborn with HI are at high risk for hypo/ hyperthermia, dehydration, respiratory distress, hypoventilation, malnutrition, hypernatremia, seizure, and skin infection. Treatment and especially nursing care of patients are very important in terms of vitality and prognosis. Comfort theory ensures that individuals who cannot meet basic human needs are met with the components of relief, contentment, and transcendence from a holistic perspective. In this case, the nursing care of the newborn diagnosed with Harlequin ichthyosis was carried out within the framework of the Comfort theory.

Keywords: Comfort theory, Harlequin ichthyosis, newborn, nursing, nursing care

Sorumlu Yazar / Corresponding Author:

Dilek Menekșe

Yayın Bilgisi / Article Info:

Gönderi Tarihi/ Received: 12/01/2021

Sakarya Üniversitesi, Sağlık Bilimleri Fakültesi, Çocuk Sağlığı ve Kabul Tarihi/ Accepted: 27/03/2021

Hastalıkları Hemşireliği Anabilim Dalı, Esentepe kampüsü, Sakarya, Online Yayın Tarihi/ Published: 05/06/2021

Türkiye

Tel: +902642956613

E-mail: dkose@sakarya.edu.tr

Atıf/ Cited: Arıkan C ve ark. Harlequin İktiyozisli Yenidoğanın Konfor Kuramına Göre Hemşirelik Bakımı: Olgu Sunumu. Online Türk Sağlık Bilimleri Dergisi, 2021;6(2):318-326. doi: 10.26453/otjhs.859650

\section{GİRIŞ}

Tüm konjenital iktiyozların en şiddetli olanı Harlequin iktiyoz (HI), nadir görülen bir genetik cilt hastalığıdır. ABCA12 geninin mutasyonuna bağlı gelişen hastalık 300.000 doğumda 1 görülmektedir. ${ }^{1,2}$ Harlequin iktiyozlu yenidoğanlar hipotermi/ hipertermi, dehidratasyon, solunum sikıntıs1, hipoventilasyon, yetersiz beslenme, hipernatremi, nöbet ve cilt enfeksiyonu açısından yüksek risk altındadırlar. ${ }^{3}$ Doğumda ya da doğum sonu ilk günlerde çoğunlukla ölümcül olabilir. ${ }^{4}$

Katharina Kolcaba kuramında konforu "bireyin gereksinimleri ile ilgili yardım, huzur sağlama ve sorunların üstesinden gelebilmeye ilişkin fiziksel, psikospiritüel, sosyal ve çevresel bütünlük içerisinde kompleks yapıya sahip beklenen bir sonuç" olarak 
tanımlamıştır. ${ }^{5-7}$ Kuramın taksonomik yapısı konfor düzeyleri (ferahlama, rahatlama, üstünlük) ve konfor boyutları (fiziksel, psikospiritüel, çevresel ve sosyokültürel) olmak üzere iki aşamada açıklanmıştır. ${ }^{6,7}$

Bu çalışmada; HI tanısı alan bir yenidoğan bebeğin gereksinimlerinin konfor kuramı kullanılarak belirlenmesi aile merkezli felsefesi ile holistik bakım çerçevesinde giderilmesi amaçlanmıştır.

\section{OLGU SUNUMU}

Yenidoğanın tıbbi verilerinin ve fotoğraflarının yayınlanabileceğine ilişkin olarak anneye ayrıntılı bilgi verilerek anneden sözlü ve yazılı onayı alınarak, gönüllü olur formu imzalatıldı.

Doğum tarihi:19.09.2019

Cinsiyeti: Erkek

Bebeğin Hastalık Öyküsü ve Soygeçmişi: Yenidoğanın annesi (yaş: 34) ve babası (yaş: 40) sağlıklı bireylerdir. Anne ev hanımıdır Anne ve baba arasında birinci dereceden (Teyze çocukları) akraba evliliği bulunmaktadır. Ailenin Bebek H. haricinde yaşayan beş çocuğu vardır. Bebek H'nin halasının farklı zamanlarda HI tanılı üç bebeği doğumu takiben ilk üç gün içerisinde öldüğü bilinmektedir. Anne gebeliği boyunca antenatal takip ve izlemlere gitmemiştir. Gestasyonel haftası bilinmeyen annenin kontraksiyonlarının başlaması üzerine doğumu normal spontan yöntem ile gerçekleştirilmiştir. Yenidoğanın doğum vücut ağırlığı 2550 gr, boyu 45 $\mathrm{cm}$ ve baş çevresi $34 \mathrm{~cm}$ 'dir. APGAR puanı birinci dakikada 9, beşinci dakikada 10'dur.

Fiziksel Değerlendirme: Yenidoğanın doğum sonrası fiziksel değerlendirmesinde yaşama bulguları kalp tepe atımı 144/dk, oksijen satürasyonu 94/dk, solunum sayısı 50/dk, vücut sicaklığ $36,4^{\circ} \mathrm{C}$ (aksillar bölge)'dir. Genel durumu aktiftir ve doğum sonrası hemen ağlamıştır. Yenidoğanın cildi zırh görünümünde olup, cilt yüzeyini sıkıca saran, sarı-beyaz renkli, derin yarıklarla birbirinden ayrılmış kalın plaklar ve bu plaklar yer yer derin fissürlerle bölünmüş şekildedir. Yenidoğanın ön fontaneli ve arka fontaneli açık olup ölçümleri sırasıyla $1 \times 1 \mathrm{~cm}$, $0,5 \times 0,5 \mathrm{~cm}$ şeklindedir.

Gözlerinde ektropion (göz kapaklarının dışa doğru dönmesi), dudaklarında eklabium (dudak mukozasının dışa dönmesi) mevcuttur. Kulak kepçesi balmumu membranla kaplı ve kulak kepçesi atrofiktir. Kalp sesleri ritmik olup S1 ve S2 doğaldır. Solunum tipi abdominal, solunum sesleri eşittir. Maserasyon alanlarından dolayı yapılan batın muayenesi suboptimal olup batın rahattır. Penis boyu kısa ve genital anomali mevcuttur. Yenidoğan refleksleri pozitiftir. Kas kitlesi doğal, tüm ekstremiteler hafif fleksiyon halindedir. El ve ayak parmaklarında belirgin kontraktürler olduğu görülmüştür.

Tıbbi Tedavi: Doğumdan hemen sonra Bebek H. radyant ısıtıcı altına alınmıştır. Doğum odasında K vitamini ve Hepatit B aşısı yapılmıştır. Spontan solunumu olan bebek mevcut bulgularla HI olarak değerlendirilmiş (Resim 1) ve üçüncü düzey yenidoğan yoğun bakım ünitesine alınmıştır.

Hasta yenidoğan yoğun bakım ünitesinde $\% 90$ nemlendirilmiş küvöze alınmıştır. Vücut sıcaklığı $36,1^{\circ} \mathrm{C}$, oksijen satürasyonu $95 / \mathrm{dk}$, kalp tepe atımı 148/dk, kan basınc1 53/25 mm/Hg ve kan şekeri 93 mg/dl olarak kaydedilmiştir. Kan gazı incelemesinde: pH: 7,29, $\mathrm{PCO}_{2}$ : 46,6 mmHg, $\mathrm{PO}_{2}: 38,9 \mathrm{mmHg}$, $\mathrm{HCO}_{3}: 20,4 \mathrm{mEq} / \mathrm{L}, \mathrm{BE}:-3,3 \mathrm{mEq} / \mathrm{L}$ ve total bilirubin değeri: $2 \mathrm{mg} / \mathrm{dl}$ olarak kaydedilmiş ve değerlendirilmiştir. Umblikal venöz katater takılarak total parenteral nutrisyon desteği başlanmıştır. Kan kültürü alınarak ampisilin (100 mg/kg/gün) ve gentamisin (4 mg/kg/gün) tedaviye eklenmiştir. Dermotoloji tarafından konsülte edilmiştir. HI açısından ailesinin de onayı alınarak $1 \mathrm{mg} / \mathrm{kg} /$ gün dozunda oral acitretin başlanmıştır. Göz hastalıkları tarafından konsülte edilen hastaya göz kapaklarının kapanmaması nedeniyle 6x1 siccapos göz jeli ve 24x1 refresh göz damlası uygulanmıştır.

Hemşirelik Girişimleri: İstanbul'da bir hastanenin üçüncü düzey yenidoğan yoğun bakım ünitesinde takip edilen Bebek H.'nin hemşirelik bakım süreci 42 gün devam etti. Yaşamsal bulgular yakından izlendi. Cilt rengi ve vücut sıcaklığı kontrol edildi. Nabız ve SPO2 monitörizasyonu yapıldı. Enfeksiyonu önlemek için yenidoğan izole bir odaya alındı ve yapılan işlemlerde aseptik teknikler kullanıldı. Küvöz içinde nem dengesi düzenli olarak kontrol edildi. Nemli küvöz ortamı sağlandı. Beslenmesine ilk gün 6,0-7,3 ml/st arası parenteral beslenme başlanan hastaya, ilk 24. saatin ardindan emme-yutma refleksi ve oral alımı değerlendirilerek enteral beslenmeye $8 \times 5 \mathrm{ml}$ anne sütü ile başlandı. Sekizinci gününde hastanın umblikal ven katateri çıkarılarak parenteral beslenme durduruldu. Tamamen enteral beslemeye geçildi. Beslenme sırasında başın 30-45 derece yükseltilmesi sağlandı. Beslenme sonrası gaz çıkarma işlemi küvöz içerisinde yapıldı. Hastanın ağrıs1 ve ajitasyonuna yönelik nonfarmokolojik yöntemler (besleyici olmayan emme, pozisyon verme) kullanılarak azaltılmaya çalışıldı. Sıvı ve elektrolit değerleri takip edildi. Yapılan kan tetkikleri sonrasında elektrolit düzeylerinin normal sınırlarda $(\mathrm{Ca}$ : 9,3 mg/dL, Na: $145 \mathrm{mmol} / \mathrm{L}, \mathrm{K}:$ 4,32 mmol/L, Mg: 
2,37 mg/dL) olduğu belirlendi. Hastanın dehidratasyon belirti ve bulguları (ağırlık kaybı, nabız, solunum, fontanel çöküklüğü, deri turgoru, gözyaşı varlığı-yokluğu, mukoza, idrar, kapiller dolma zamanı) gözlenerek değerlendirildi. Hasta cilt yüzeyindeki derin fissürlerden olabilecek kanama bulgusu yönünden kontrol edildi.

Konfor Kuramı Doğrultusunda Hemşirelik Bakımı: Hasta bireyin gereksinimlerinin konfor kuramının aşamaları doğrultusunda tanılanması, girişimlerinin planlanması, uygulanması bakımın ve yenidoğanın yaşamını olumlu yönde etkiler. ${ }^{6,7} \mathrm{Bu}$ kapsamda konfor kuramının taksonomik yapısına göre HI'li yenidoğanın hemşirelik bakımı Tablo 1'de verilmiştir.

Bebeğe özel günlük banyo uygulaması her gün sabah saat 06:00 da, benmari usulü 1sıtılmış steril su ile iki hemşire ve bir personel eşliğinde yapıldı. Uygulama sırasında tüm ekip üyeleri koruyucu ekipman (önlük, maske, bone, eldiven) kullandı. İşlem öncesinde dezenfekte edilmiş bir kot küvöz içerisine alt pedi ve steril yeşil örtü serildi. Yeşil örtü üzerine bebek yatırıldı.

Uygun sicaklıktaki $\left(38-40^{\circ} \mathrm{C}\right) \mathrm{su}$, bebeğin cilt üzerine dökülerek yapılan vücut banyosu yaklaşı 5-10 dakikada tamamlandi. Banyo yapılan odanın 1sisı 22 $-26^{\circ} \mathrm{C}$ arasında olması sağland. Yenidoğan banyo sonrası hemen küvözüne alındı. Vücut yüzeyi baştan ayağa doğru steril bir havlu ile tampon hareketlerle yumuşak bir şekilde kuruland. Kurulama işleminden sonra bebeğin cilt yüzeyi steril bactigras tül ile sarıld1 (Resim 2).

Sıvı ve katı vazelin karışımı ile üç saatte bir cildine sürülerek sürekli nemli kalması sağlandı. Ciltteki basıyı azaltmak için iki saatte bir pozisyonu değiştirildi. Cilt yüzeyinin sürekli nemli kalması sağlanan hastanın cildindeki balmumu membranlar postnatal 6. ve 9. günlerinde gövdesinden dökülmeye başladı (Resim 3, Resim 4).

Taburculuk eğitimi, hastanın hastaneye yatması ile başlayan, taburculuk sonrası bakımını iyi şekilde sürdürebilmesi için hazırlanan bir süreçtir. Hastanın taburcu olduktan sonra evde yaşayabileceği sorunları önceden tahmin ederek, hastaneden ayrilabilmesi ve bakımını evde sürdürebilmesi için hastane ve ev arasında bağlantı sağlayacak sistemli bir eğitime gereksinim vardır. ${ }^{8}$

Ebeveynlere verilen eğitim konuları;

-Anne sütü önemi ve emzirme

-Süt saklama koşulları

-A ğız bakımı

-Ağr1 yönetimi
-Bebeğin uykusu

-Bebeğin aşıları, gelişimsel izleminin yapılması ve doktor kontrolleri

-Cilt bakımı, banyo, giysilerinin değiştirilmesi, ortam isis1

-Enfeksiyon kontrolü

-Kanama belirti ve bulguları

-Gözlenebilecek acil durumlarda yapılması gerekenler başlıklarını içermiştir.

\section{TARTIŞMA VE SONUÇ}

HI'li yenidoğanlar hipotermi/hipertermi, dehidratasyon, solunum sikıntısı, yetersiz beslenme, hipernatremi, nöbet ve cilt enfeksiyonu açısından yüksek risk altındadırlar. ${ }^{7} \mathrm{Bu}$ komplikasyonların önlenmesinde ve yaşamın uzatılmasında hemşirelik bakımı önemlidir. Literatürde etkilenen bebeklerin doğumda ya da doğumdan kısa bir süre sonra hayat1nı kaybettikleri bildirilmiştir. ${ }^{1,3,9} \mathrm{Bu}$ olguda yatış süreci boyunca yaşamını tehdit eden dehidratasyon, enfeksiyon ve solunum yetmezliği gibi komplikasyonlar görülmemiştir. $\mathrm{Bu}$ sonuç bakımın multidisipliner, kanıt temelli bir yaklaşımla takip edilmesiyle ilişkilendirilebilir. Konfor hemşirelik bakımının ayrılmaz bir parçası olup konforun artmas1 bakım kalitesinin göstergesidir. ${ }^{5-7} \mathrm{HI}$ 'li hastaların koruyucu ve destekleyici bakım ile yaşam kalitesinin arttırılabileceği belirtilmiştir. ${ }^{3,9}$ Kolcaba'nın Konfor Kuramı'na temellenen hemşirelik bakımı HI tanılı hastanın bakım sürecine sistematik bir çerçevede değerlendirme ve yaklaşım kazandırmakla birlikte holistik açıdan tüm boyut ve düzeyleri ile konforun arttırılmasına da katkı sağlamıştır. Konfor kuramı bakım sürecinde farklı bir eleştirel bir bakış açısı kazandırmıştır. $\mathrm{Bu}$ bağlamda olgu sunumunun yenidoğan hemşirelerine katkı sağlayacağını düşünmekteyiz.

Etik Komite Onayı: Çalışmamız olgu sunumu olduğu için etik kurul onayı gerekmemektedir. Yenidoğanın annesinden sözlü ve yazılı onam alınmıştır. Hastanenin yenidoğan yoğun bakım ünite sorumlusundan izin alınmıştır.

Çıkar Çatışması: Yazarlar çıkar çatışması bildirmemişlerdir.

Yazar Katkıları: Fikir - DM, NÇ; Veri toplanması ve işlemesi - CA; Yazıyı yazan - CA, DM, NÇ

Hakem değerlendirmesi: Dış bağımsız .

Teşekkür: Bebeğin ebeveynlerine bilgi ve fotoğraf paylaşılmasına izin verdikleri için çok teşekkür ederiz. 


\section{KAYNAKLAR}

1. Shruthi B, Anita Dalal BRN, Limbani N. Harlequin ichthyosis: A rare case. Turk J Obstet Gynecol. 2017;14:138-140. doi:10.4274/ tjod.63004

2. Ahmed H. O'Toole EA. Recent Advances in the genetics and management of harlequin 1chthyosis. Pediatric Dermatology. 2014;31 (5):539-546. doi:10.1111/pde.12383

3. Salehin $\mathrm{S}$, Azizimoghadam A, Abdollahimohammad A, Babaeipour-Divshali M. Harlequin ichthyosis: Case report. J Res Med Sci. 2013;18(11):1004-1005.

4. Devika P, Marla J, Tor S. Harlequin ichtiyosis. J Am Acad Dermatol. 2015;72:200.

5. Kolcaba K, Wilson L. Comfort care: A framework for perianesthesia nursing. Journal of Perianesthesia Nursing, 2002;17:102-111. doi:10.1053/jpan.2002.31657

6. Kolcaba KYA Taxonomic Structure for the Concept Comfort. Image: The Journal of Nursing Scholarship. 1991;23(4):237-240. doi:10.1111/j.1547-5069.1991.tb00678.x

7. Kolcaba K. Comfort theory and practice. A vision for holistic care and research. Springer Publishing Company: Newyork; 2003.

8. Yalçın S, Arpa Y, Cengiz A, Doğan S. Hemşirelerin hastaların taburculuk eğitim gereksinimlerine yönelik görüşleri ile hastaların eğitim gereksinimlerine yönelik görüşlerinin karşılaşt1rılması. Hemşirelikte Eğitim ve Araştırma Dergisi. 2015;12(3):204-209.

9. Torun S, Demiroğlu H. Newborn with harlequin 1chthyosis and the nursing care. J Pediatr Emerg Intensive Care Med. 2018;5:134 -139. doi:10.4274/cayd.78941

10. Wilkinson MJ, Barcus L. PEARSON Hemşirelik Tanıları El Kitabı. In: Kapucu S, Akyar İ, Korkmaz F, editors. 11nt ed. Ankara: Pelikan Yayınevi; 2018:1081-1087. 


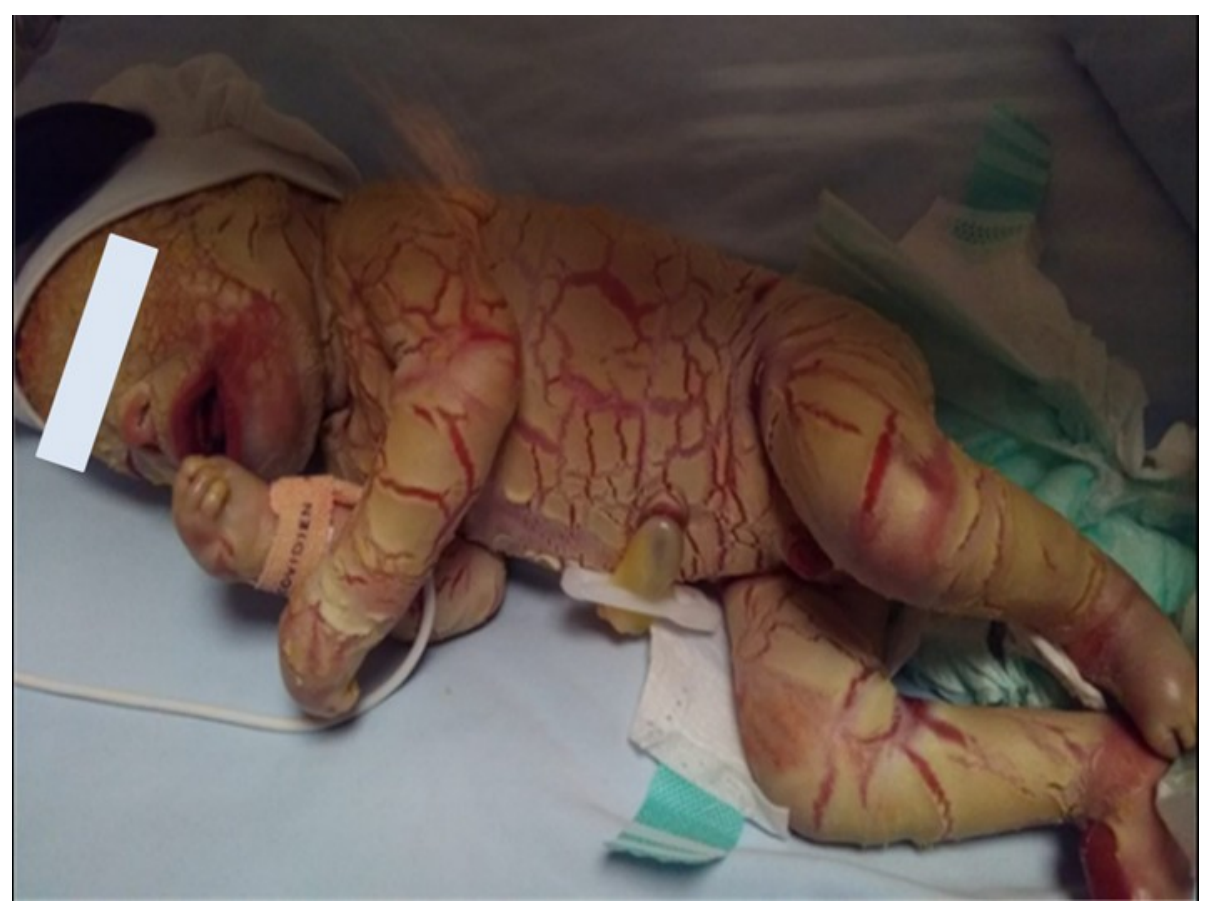

Resim 1. Doğumda deride sert plaklar, fissürler, gözlerde belirgin ektropiyon ve dudaklarda eklabium. 


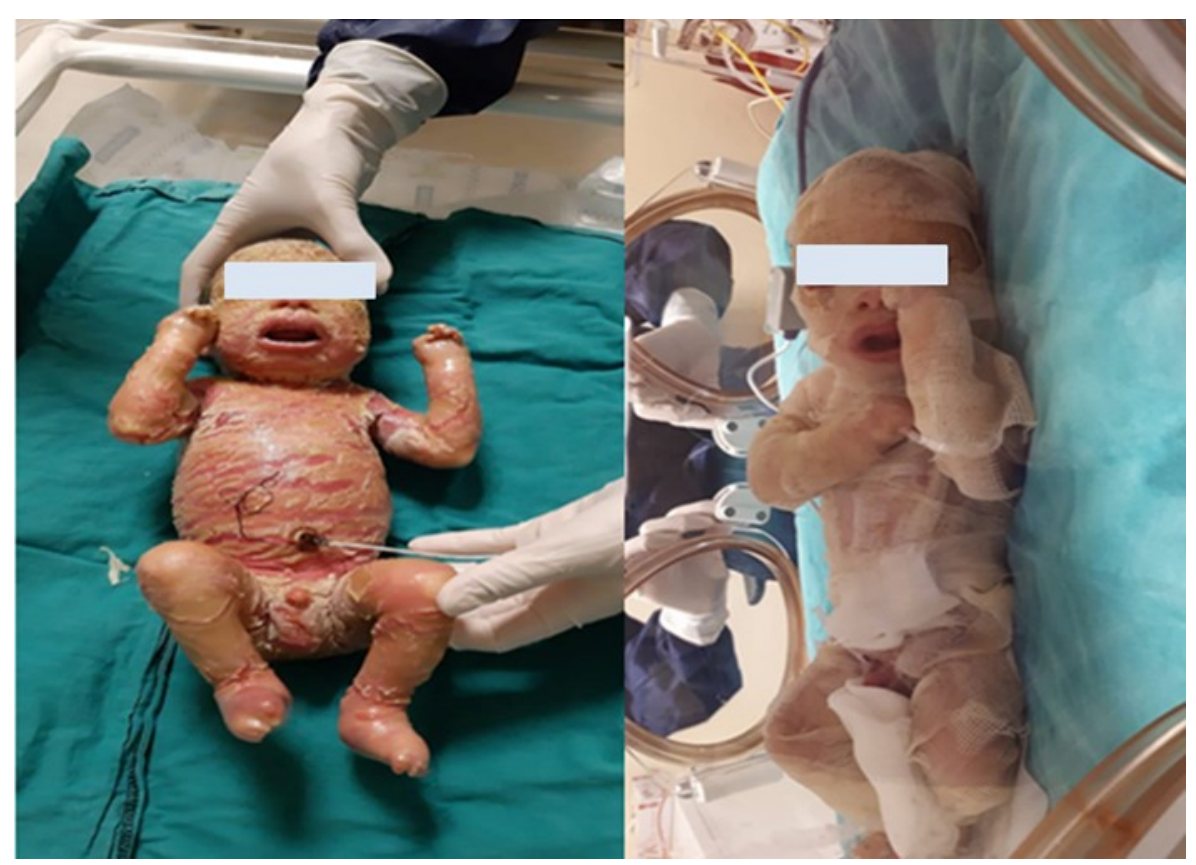

Resim 2. Özel vücut banyosu hazırlığı ve Bactigras tül ile sarılmış cilt yüzeyi. 


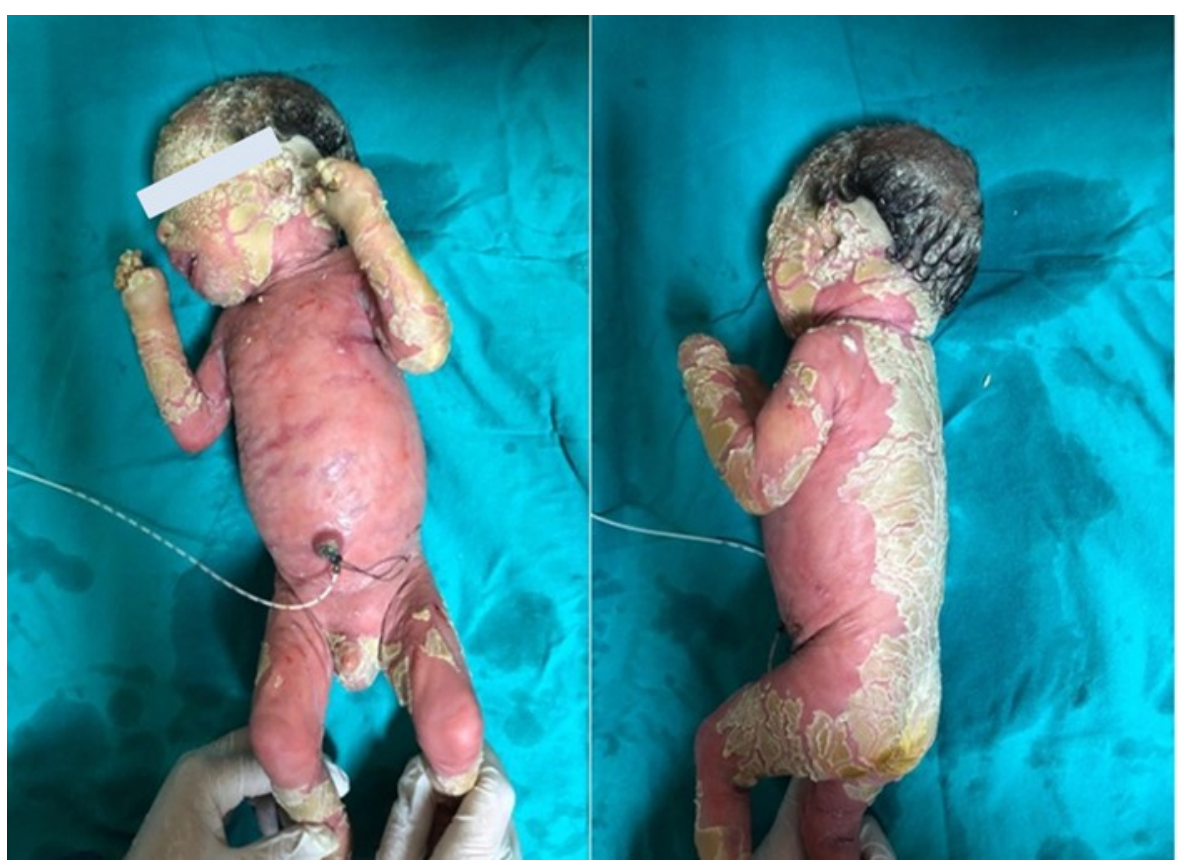

Resim 3. Postnatal 6. gündeki cilt yüzeyi. 


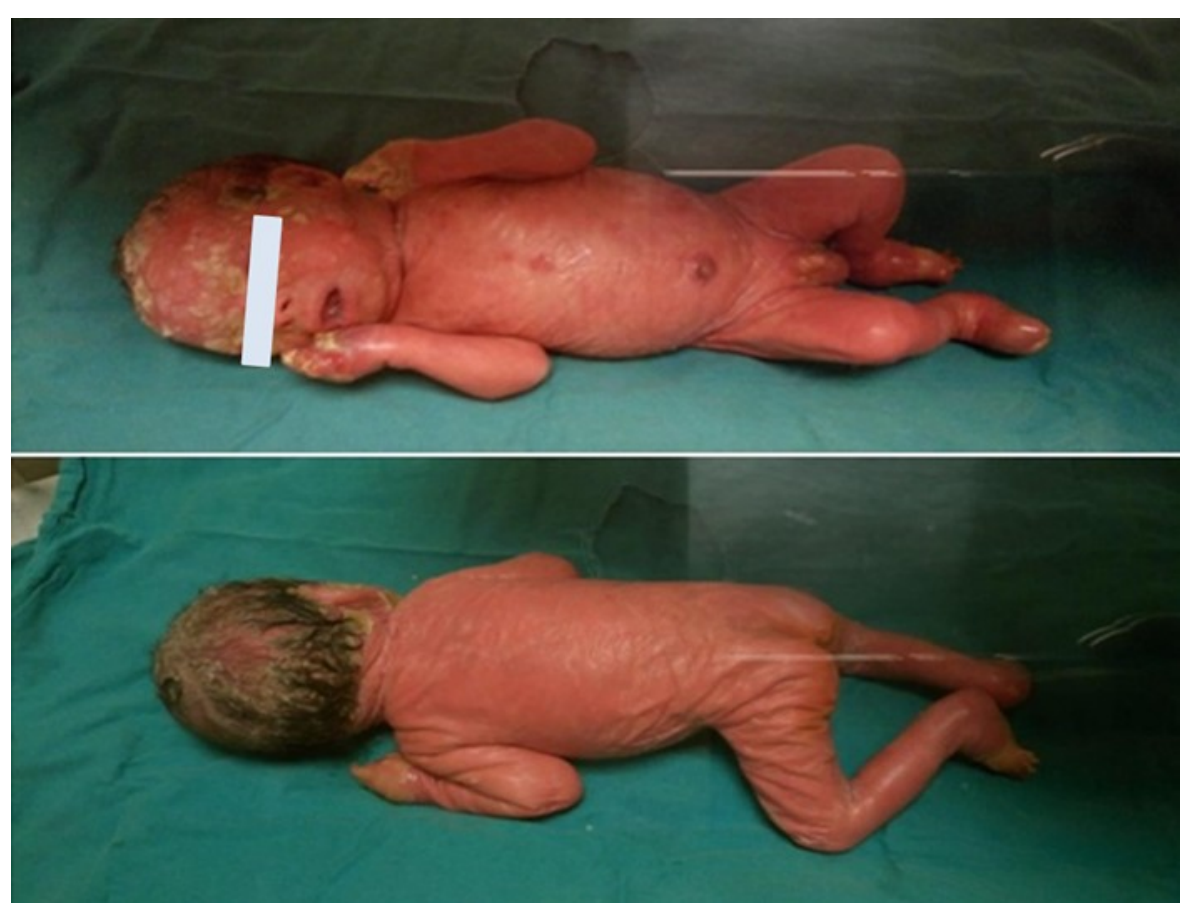

Resim 4. Postnatal 9. gündeki cilt yüzeyi. 
Tablo 1. Konfor Kuramı'nın taksonomik yapısına göre Harlequin iktiyozisli yenidoğanın hemşirelik bakımı. ${ }^{6,10}$

\begin{tabular}{|c|c|c|c|}
\hline BOYUTLARI & \multicolumn{3}{|c|}{ DÜZEYLERİ } \\
\hline & Ferahlama & Rahatlama & Üstünlük \\
\hline \multicolumn{4}{|l|}{ Fiziksel } \\
\hline Ağr1 & $\begin{array}{l}\text { Hastanın ağrısını azaltmak amaçlı } \\
\text { emzik kullanılması ve prone pozisyo- } \\
\text { nu verilmesi }\end{array}$ & $\begin{array}{l}\text { Hastanın ağrısına yönelik } \\
\text { yapılan uygulamalar sonrası } \\
\text { rahatlamasının sağlanması }\end{array}$ & $\begin{array}{l}\text { Ağrı oluşumunun engel- } \\
\text { lenmesi }\end{array}$ \\
\hline $\begin{array}{l}\text { Gereksiniminden } \\
\text { Az Beslenme }\end{array}$ & $\begin{array}{l}\text { Emme-yutma refleksi aktif olan has- } \\
\text { tanın oral beslenmesinin sağlanması } \\
\text { Annenin bebeğini emzirmesinin sağ- } \\
\text { lanması }\end{array}$ & $\begin{array}{l}\text { Hastanın oral beslenmesi ve } \\
\text { emzirilmesi sağlanarak rahat- } \\
\text { latılması }\end{array}$ & $\begin{array}{l}\text { Anne ile bebek uyumu- } \\
\text { nun artması ile yeterli } \\
\text { beslenmenin sağlanması }\end{array}$ \\
\hline $\begin{array}{l}\text { Oral Mukoz } \\
\text { Membranda Bo- } \\
\text { zulma }\end{array}$ & $\begin{array}{l}\text { Distile su ile ıslatılmış spanç ile ağız } \\
\text { bakımı verilmesi }\end{array}$ & $\begin{array}{l}\text { Ağız bakımı yapılan hastanın } \\
\text { rahatlatılmasının sağlanması }\end{array}$ & $\begin{array}{l}\text { Oral mukoz membran } \\
\text { bozulmasinın engellen- } \\
\text { mesi }\end{array}$ \\
\hline $\begin{array}{l}\text { Doku Bütünlüğün- } \\
\text { de Bozulma }\end{array}$ & $\begin{array}{l}\text { Kuru kalan cildin nemlendirilmesi } \\
\text { için üç saatte bir sıv1-katı vazelin } \\
\text { kullanılması ve günlük özel vücut } \\
\text { banyosu yaptırılması }\end{array}$ & $\begin{array}{l}\text { Yapılan nemlendirme ve ban- } \\
\text { yo sonrasında hastanın rahat- } \\
\text { lamasının sağlanması }\end{array}$ & $\begin{array}{l}\text { Skala kaplı cildin za- } \\
\text { manla iyileşmesi }\end{array}$ \\
\hline $\begin{array}{l}\text { S1v1 Elektrolit } \\
\text { Dengesizliği Riski }\end{array}$ & $\begin{array}{l}\text { Hastanın alması gereken sıvı miktarı- } \\
\text { na göre hidrasyonun sağlanması } \\
\text { Kan tetkikleri yapılarak elektrolit } \\
\text { düzeyinin takip edilmesi }\end{array}$ & $\begin{array}{l}\text { Hastanın yeterli beslenmesi } \\
\text { sağlanarak rahatlaması }\end{array}$ & $\begin{array}{l}\text { S1v1 elektrolit dengesiz- } \\
\text { liğinin görülmemesi }\end{array}$ \\
\hline Kanama Riski & $\begin{array}{l}\text { Skala kaplı cildin derin fissürlerle } \\
\text { bölünmüş şekilde olmasından kay- } \\
\text { naklı oluşabilecek kanamaların takip } \\
\text { edilmesi }\end{array}$ & $\begin{array}{l}\text { Kuru olan cildin bactigras tül } \\
\text { ile sarılıp nemli kalmasının } \\
\text { sağlanması }\end{array}$ & $\begin{array}{l}\text { Kanamanın görülmeme- } \\
\text { si }\end{array}$ \\
\hline Hipertermi Riski & $\begin{array}{l}\text { Hastanın vücut sıcaklığının sık aralık- } \\
\text { larla takip edilmesi }\end{array}$ & $\begin{array}{l}\text { Küvöz ısının bebeğin durumu- } \\
\text { na göre ayarlanarak hastanın } \\
\text { rahat kalmasının sağlanması }\end{array}$ & $\begin{array}{l}\text { Hiperterminin görülme- } \\
\text { mesi }\end{array}$ \\
\hline \multicolumn{4}{|l|}{ Çevresel } \\
\hline $\begin{array}{l}\text { Uyku Örüntüsün- } \\
\text { de Bozulma }\end{array}$ & $\begin{array}{l}\text { Hastanın izole bir odada kalması, } \\
\text { bakım saatleri haricinde odanın 1şı̆ğ- } \\
\text { nın kapalı tutulması ve küvöz örtüsü } \\
\text { kullanılarak hastanın uyumasının } \\
\text { sağlanması }\end{array}$ & $\begin{array}{l}\text { Yapılan uygulamalar sonra- } \\
\text { sinda hastanın uykusunun } \\
\text { düzenlenmesi ve rahatlamas1- } \\
\text { nın sağlanması }\end{array}$ & $\begin{array}{l}\text { Uyku düzeninin sağlan- } \\
\text { ması }\end{array}$ \\
\hline $\begin{array}{l}\text { Enfeksiyon Alma } \\
\text { Riski }\end{array}$ & $\begin{array}{l}\text { Yapılacak girişimlerde ve bakım } \\
\text { verirken koruyucu ekipmanlar } \\
\text { (koruyucu önlük, eldiven, maske, } \\
\text { bone) kullanılması } \\
\text { Tüm invaziv girişimlerde aseptik } \\
\text { teknik kurallarına uyulması }\end{array}$ & $\begin{array}{l}\text { Enfeksiyonu önlemek için } \\
\text { yapılan girişimler sonucunda } \\
\text { hastanın rahatının sağlanması }\end{array}$ & $\begin{array}{l}\text { Enfeksiyon oluşumunun } \\
\text { önüne geçilmesi }\end{array}$ \\
\hline \multicolumn{4}{|l|}{ Sosyo-Kültürel } \\
\hline $\begin{array}{l}\text { Yetersiz Aile- } \\
\text { Bebek Etkileşimi }\end{array}$ & $\begin{array}{l}\text { Ailenin harlequin iktiyozlu } \\
\text { yenidoğana ilişkin rol ve sorumluluk- } \\
\text { larını yerine getirmesi, yenidoğanın } \\
\text { bakım sürecine dahil olması } \\
\text { Ailenin yenidoğanı kucaklayabilme- } \\
\text { leri için cesaretlendirilmesi }\end{array}$ & $\begin{array}{l}\text { Aile ile bebek uyumunun } \\
\text { sağlanarak hastanın rahatlatıl- } \\
\text { ması }\end{array}$ & $\begin{array}{l}\text { Aile-bebek etkileşiminin } \\
\text { sağlanması }\end{array}$ \\
\hline \multicolumn{4}{|l|}{ Psiko-spiritüel } \\
\hline $\begin{array}{l}\text { Ailenin yaşadı̆̆ } 1 \\
\text { anksiyete }\end{array}$ & $\begin{array}{l}\text { Ailenin harlequin iktiyozlu } \\
\text { yenidoğana ilişkin endişelerini ifade } \\
\text { etmesinin sağlanması } \\
\text { Aileye hastalık hakkında bilgilendir- } \\
\text { me yapılması }\end{array}$ & $\begin{array}{l}\text { Ailenin yaşadığı endişenin } \\
\text { giderilmesi ve ailenin rahatla- } \\
\text { mas1 }\end{array}$ & $\begin{array}{l}\text { Ailenin anksiyete ile baş } \\
\text { etmesinin sağlanması }\end{array}$ \\
\hline
\end{tabular}

